\title{
Thinking magically or thinking scientifically: Cognitive and belief predictors of complementary and alternative medicine use in women with and without cancer diagnosis
}

Vladimíra Čavojová ( $\square$ vladimira.cavojova@savba.sk)

Centre of Social and Psychological Sciences SAS

\section{Zuzana Kaššaiová}

Centre of Social and Psychological Sciences SAS

Jakub Šrol

Centre of Social and Psychological Sciences SAS

\section{Eva Ballová Mikušková}

Centre of Social and Psychological Sciences SAS

\section{Research Article}

Keywords: complementary and alternative medicine (CAM), cancer diagnosis, scientific reasoning, pseudoscientific beliefs, magical beliefs, locus of control

Posted Date: December 3rd, 2021

DOI: https://doi.org/10.21203/rs.3.rs-1049483/v1

License: (1) This work is licensed under a Creative Commons Attribution 4.0 International License.

Read Full License 


\section{Abstract \\ Background}

Complementary and alternative medicine (CAM) is popular among the general population and patients with various diseases, but our understanding of the predictors of CAM use for the population of women with or without cancer diagnosis is still quite limited. This paper examines predictors of attitudes toward and use of CAM, including cognitive factors (scientific reasoning, health literacy, locus of control), beliefs (holistic and magical health beliefs pseudoscientific beliefs, and trust in doctors), sociodemographic factors, and cancer diagnosis.

\section{Methods}

The sample consisted of 177 women (103, 58.2\% without cancer, $74,41.8 \%$ with cancer diagnosis; Mage $=38.81, \mathrm{SD}=11.43$ ).

\section{Results}

Pseudoscientific/magical beliefs and external locus of control were the strongest predictors of positive attitudes toward CAM and its higher use, as well as preference for CAM instead of conventional treatment. Cancer diagnosis predicted only higher CAM use, but not more positive attitudes to CAM, nor preference for CAM instead of conventional medicine. There was no difference between women with and without cancer diagnosis in using CAM after we controlled for age and education. Women in our sample had a similar level of magical beliefs, holistic health beliefs, and attitudes toward CAM regardless of their cancer diagnosis. However, women with cancer had significantly more pseudoscientific beliefs than women without cancer and a higher external locus of control over their health.

\section{Conclusion}

Women who have an inclination toward holistic and magical beliefs about health tend to favor CAM treatments independently of the cancer diagnosis, although the diagnosis of cancer also contributes to their higher use of CAM. In other words, it seems improbable that women would turn toward CAM treatment only after being diagnosed with cancer.

\section{Background}

Over the last decades, the use of complementary and alternative medicine (CAM) has grown in popularity among healthy populations (Abheiden et al., 2020) and patients with various diseases (Buckner et al., 2018). Complementary and alternative medicine can be defined as a group of medical and healthcare 
treatments, products, and practices that are not considered as a part of conventional medicine (Fouladbakhsh \& Stommel, 2008).

Despite the increasing use of CAM in a wide variety of symptoms and conditions, cancer patients represent a group in which it is particularly widespread (Fox et al., 2013; Matsuno et al., 2012). The global prevalence of CAM use among cancer patients ranges from $7 \%$ to $80 \%$, but it depends on factors such as the definition of CAM, type of cancer, or sampling methods (Berretta et al., 2016; Harris et al., 2012; Keene et al., 2019). Although CAM use is higher among women (Bishop \& Lewith, 2010; Kristoffersen et al., 2014), our understanding of the predictors of CAM use for the population of women with or without cancer diagnosis is still quite limited. Women diagnosed with cancer may have different motivations and higher stakes in their health decisions including those regarding the use of CAM than women without cancer who may use CAM for less severe ailments. Because of a paucity of research focusing on both women with and without cancer (Fouladbakhsh \& Stommel, 2008), in this paper, we study the predictors of CAM use and CAM attitudes in women with and without a cancer diagnosis. Moreover, we examine the potential differences between these two groups in the cognitive and belief factors related to CAM use.

Whether the use of unconventional medical practices is harmful or it actually helps people to feel better (e.g., as a placebo treatment) has been debated for some time. Medical skepticism toward alternative medicine is usually based on a lack of evidence for the efficacy of CAM therapies; and in the worse cases, it can even pose risk to the patients (Meijerman et al., 2006; Smith et al., 2015). For example, individuals with symptoms using CAM may postpone seeking medical attention (Latte-Naor et al., 2018). Moreover, certain CAMs may interfere with conventional medicine and produce adverse effects, especially if doctors are not informed about the simultaneous use of CAM (Dubois et al., 2019). Ironically, many users feel that "natural" equals "safe" and cannot do any harm (Ernst, 2007; Myers \& Cheras, 2004), which is often the reason for their choice of CAM. Although CAM use can be potentially harmful, its danger lies mostly if used instead (and not with) the conventional treatment. According to Johnson et al. (2018), patients who initially chose alternative medicine without conventional therapies for the treatment of curable cancer (such as breast cancer, colorectal, and lung cancer) had a significantly increased risk of death. However, to date, a limited number of studies evaluated the use of alternative medicine (as the primary treatment), due to a lack of data and hesitancy of users to confess non-medical therapies. Therefore, as a secondary dependent measure of CAM use, we also included a question, whether women use CAM treatment or conventional medicine as the main method of treatment.

The purpose of this study is, therefore, to examine predictors of attitudes toward, use of, and preference for CAM, including cognitive factors (scientific reasoning, health literacy, locus of control), beliefs (magical thinking, holistic health beliefs, pseudoscientific beliefs, and trust in doctors), sociodemographic factors, and cancer diagnosis. Identifying predictors is important for exploring similarities and differences among women with and without cancer diagnosis and contributes to a greater understanding of how and why CAM is used. Before we proceed to introduce our study in more detail, we briefly review the previous research on socio-demographic and psychological factors associated with the use of CAM, as well as studies that examined differences in CAM use among women with and without a cancer diagnosis. 


\section{Socio-demographic factors associated with increased CAM use}

Most medical research focused on identifying which group of people is most prone to using CAM and it was found that being female (Boutin et al., 2000; MacLennan et al., 2002, 2006; Xue et al., 2007), middleaged (Astin, 1998; Bishop \& Lewith, 2010), having a higher income (MacLennan et al., 2002; Thomas \& Coleman, 2004; Xue et al., 2007), and more education (Astin, 1998; MacLennan et al., 2002, 2006; McFarland et al., 2002), were associated with increased CAM use.

Several studies examined differences between patients with cancer and the general population in their CAM use and found out that cancer patients and cancer survivors have a greater tendency to utilize CAM than individuals in the general population (Buckner et al., 2018; Fox et al., 2013; Matsuno et al., 2012). The reasons for CAM use were mostly related to increasing the body's ability to fight a disease, relief from symptoms and side effects of treatment, improving emotional well-being and a desire for greater control. Similarly, as for the general population, CAM use among women with cancer was associated with higher education level (Conrady \& Bonney, 2017), higher income, full-time job (Rakovitch et al., 2005), but with younger age (Latte-Naor et al., 2018; Pedersen et al., 2009).

\section{Psychological predictors of CAM use}

Why do people choose alternative medicine over conventional treatment when it has been repeatedly shown in large and controlled studies that it does not have the same efficiency and can be even harmful? People often use CAM to improve their quality of life, promote health, manage distress and disease symptoms, or avert disease recurrence (Buckner et al., 2018; Fouladbakhsh \& Stommel, 2009). It seems that one of the crucial predictors of CAM use is the belief about its efficacy based on one's spiritual outlook. For example, Astin (1998) found that a holistic orientation to health, interest in spirituality, and personal growth psychology were all among predictors of alternative medicine use. Moreover, he argues that only a minority of people rely on CAM as a primary treatment and that people are drawn to use CAM not out of dissatisfaction with conventional treatment, but because alternative treatments seem to be more congruent with their philosophical outlook on life, beliefs, and values.

However, Verhoef et al. (2005) stress that there is a difference between the use of CAM and actual belief in its efficacy. For example, in Čavojová $\square$ s and Ersoy $\square$ s (2020) study, scientific reasoning predicted belief in CAM but not the use of CAM. Pro-CAM attitudes were a stronger predictor than CAM use also in another study focusing on other health behaviors, such as vaccination (Bryden et al., 2018). While attitudes are a strong predictor of behavior (theory of planned behavior; Ajzen, 2002), there is usually a gap between intentions and behavior, therefore it is reasonable to expect a stronger effect of some beliefs on forming of pro-CAM attitudes, while their association with CAM use may be weaker. Therefore, we examined CAM attitudes and CAM use separately.

Moreover, there is now quite strong evidence that various beliefs that are in contradiction with (or at least lacking any substantial support from) current scientific knowledge correlate together (Čavojová, Šrol, \& Jurkovič, 2020a; Lobato et al., 2014; Šrol, 2020). Some researchers suggested that believing CAM shares 
common ground with paranormal beliefs - either in general or applied to health. Indeed, positive correlations between beliefs in CAM, paranormal beliefs, magical food and health beliefs, and intuitive thinking were found in some studies (Bryden et al., 2018; Lindeman, 2011; Saher \& Lindeman, 2005). Similarly, Hyland et al. (2003) developed a new measure for CAM and found that belief in the scientific basis of CAM correlates positively with holistic health beliefs and vitamin use, while it correlates negatively with antibiotic use. Also, pseudoscientific beliefs have been shown to be related to questionable health practices (Čavojová et al., 2022; Sugavanam et al., 2020; Teovanović et al., 2020; Travers et al., 2016). CAM has been found to correlate also with anti-vaccination attitudes (Bryden et al., 2018). Thus, we included several subsets of this kind of epistemically suspect beliefs specifically related to health in this study. Thus, we expect that positive attitudes toward CAM, as well as higher CAM use, will be associated with various kinds of magical/pseudoscientific beliefs.

Moreover, several studies (Catt et al., 2006; Henderson \& Donatelle, 2003) found that 'feeling more in control' was associated with CAM use among women with cancer. Similarly, Pitel and Ballová Mikušková (2021) found a relationship between chance health locus of control and adverse health behaviors, moreover, two external dimensions of locus of control (powerful others and chance) and negative emotionality were stronger predictors of adverse health behaviors than cognitive distortion. Therefore, we expect that internal locus of control will be associated with increased CAM use, but we will explore the differences in locus of control between the women with and without a cancer diagnosis.

A lack of trust in the medical professions can be another reason why patients ask for a second opinion or they can be prone to use CAM (van den Brink-Muinen \& Rijken, 2006). People also can trust alternative practitioners because of their holistic views and therefore, they may feel that they understand the diseases better. However, due to the lack of research, we do not have enough evidence that clarifies the relationship between trust in doctors, CAM use, and attitudes toward CAM.

On the other hand, also cognitive factors play an important role in health decisions. People with better scientific reasoning hold beliefs more consistent with scientific consensus and have more scientific knowledge (Dieckmann \& Johnson, 2019; Downs et al., 2008; Drummond \& Fischhoff, 2017; Kaygısız \& Gürkan, 2018). Scientific reasoning seems to be a stronger predictor of health-related unfunded beliefs than analytic thinking (Čavojová, Šrol, \& Ballová Mikušková, 2020). Beliefs seem to be the most important driving force for behavior, even when cognitive factors are taken into account. For example, Čavojová and Ersoy (2020) found that while scientific reasoning negatively predicted belief in the efficacy of CAM, its role in actual reported use of CAM diminished after religious faith was introduced to the model. On the other hand, the role of cancer health literacy is inconclusive. While some studies showed that the patients with higher CAM use have significantly lower health literacy scores (Conrady \& Bonney, 2017; Wilhelm \& Euteneuer, 2021), others showed that they also can have more positive attitudes toward CAM because they tend to rely on rapidly available and unscientific, easily found sources of information (Dişsiz \& Yilmaz, 2016; Jablotschkin et al., 2020). Therefore, we will also examine the role of cancer health literacy for both groups of women and its association with CAM use and attitudes. 


\section{Comparing women with cancer and without cancer}

Although several studies suggested that women with cancer tend to have increased use of CAM (Buckner et al., 2018; Fox et al., 2013; Matsuno et al., 2012), the psychological factors behind this finding have not been yet conclusively established. While it seems sensible to expect that women with a cancer diagnosis will turn to all means that can help them to get better or at least alleviate the symptoms of illness or its treatment, little is known whether any actual shift in beliefs surrounding CAM and health occurs. Moreover, several antagonistic factors can be at play: for example, women diagnosed with cancer may be more prone to learn about their illness from their physicians or other sources that could increase their health literacy and reasoning, which is connected with less CAM use and pseudoscientific health beliefs (Čavojová, Šrol, \& Ballová Mikušková, 2020; Čavojová \& Ersoy, 2020). On the other hand, emotional factors, such as helplessness and loss of control can override rational processes and lead to higher acceptance of magical and pseudoscientific beliefs (e.g. Šrol et al., 2021) that can lead to increased CAM use. This is in line with terror management theory (Greenberg et al., 1997), which argues that when confronted with our own mortality and existential anxiety, people tend to cling to beliefs that transcend us. Our aim in this paper is to address these unknown issues and explore the differences between women with and without cancer diagnosis not only in CAM use but also in their beliefs, locus of control, trust in doctors, and cancer health literacy.

\section{Methods}

\section{Participants and procedure}

We recruited the participants for our study via social networks and specialized groups for people diagnosed with cancer (e.g. League against cancer, etc.) to enroll women with some experience with cancer. We employed a snowball technique and participants were encouraged to share the survey with their friends and relatives. The survey was run on the Qualtrics platform and it was open from May to the end of June 2021. Prior to conducting research, it was approved by the Ethical Committee of the Centre of Social and Psychological Sciences SAS.

The final sample consisted of 177 women. One hundred and three women were not diagnosed with cancer (58.2 \%) and 74 women (41.8\%) had been diagnosed with some type of cancer. The mean age of our sample was $38.81(S D=11.43)$. Most of the women with cancer have been diagnosed with breast cancer $(N=55)$, five were diagnosed with cervical cancer, and the rest $(N=17)$ had other kinds of cancer (ovaries, lungs, colon, lymphoma, etc.).

\section{Materials}

The use and attitudes toward complementary and alternative medicine

The use of CAM. We used The International Questionnaire to Measure Use of Complementary and Alternative Medicine (I-CAM-Q) modified by Bryden et al., (2018), which contains three sections: (1) 
provision of CAM services (homeopath, acupuncturist, herbalist, spiritual healer, chiropractor, naturopath, hypnotherapist, body manipulation therapies, hypnotherapy, body manipulation therapies such as Bowen Therapy or Reiki (excluding massage or physiotherapy), therapeutic massage, and other (please specify); (2) use of CAM products (herbs/herbal medicine; vitamins/minerals; homeopathic remedies; remedies for weight-loss, magnetic rings/bracelets, flour-free or chlorine-free distilled water for medical purposes, master mineral solutions (or its alternatives), other (please specify); (3) self-help practices (meditation, yoga or tai chi, detox or cleansing diet, prayer for your own health, relaxation techniques or visualization, aromatherapy, any form of traditional or spiritual healing ceremony). Participants rated every item on 3point scale ( 1 = never, $2=$ more than 12 months ago, $3=$ in the last 12 months). For the purposes of all present analyses, we dichotomized the response scale so that participants who reported never using CAM practices and products were assigned a score " 0 " and those who reported using it were assigned " 1 " for that particular item regardless of whether they used it more than a year ago or less than a year ago. Three sub-scale totals were calculated for the use in this study: services (Cronbach's alpha $=.58$ ), products (Cronbach's alpha $=.45$ ), and self-help practices (Cronbach's alpha $=.64)$. Cronbach's alpha for the total scale was .73, so for some of the subsequent analyses, we also used the total CAM use score.

CAM attitudes subscale (Hyland et al., 2003) contained 6 questions measuring attitudes regarding the efficacy and desirability of CAM, e.g. "Complementary medicine should only be used in minor ailments and not in the treatment of more serious illness". Participants answered on 5-point scale $(1=$ totally disagree, $5=$ totally agree). Four items were recoded, so that a higher score reflected more positive attitudes toward CAM. Cronbach's alpha was .80 .

Preference for CAM over classical medical treatment. We included one additional question to distinguish whether participants used the above-mentioned services, products, and self-help as the main method of treatment or as a supplement to classical medical treatments, with choices ranging from 1 (= exclusively alternative treatments) to 5 (= exclusively classical medicine), with 3 (= both according to circumstances).

Magical and pseudoscientific beliefs about health.

Magical belief health subscale (Lindeman et al., 2000) contained 10 questions related to health, e.g. "Colors change the organism's energy vibration in a direction that is beneficial to health." Participants answered on 5-point scale ( $1=$ totally disagree, $5=$ totally agree $)$. Cronbach's alpha was .88 .

The holistic health belief subscale (Hyland et al., 2003) contained 5 questions measuring belief in a holistic model of health, e.g. "Positive thinking can help you fight off a minor illness." Participants answered on 5-point scale ( 1 = totally disagree, 5 = totally agree). Cronbach's alpha was .74 .

Pseudoscientific beliefs scale (Fasce \& Picó, 2019) consisted of 30 questions related to various contemporary pseudoscientific treatments and beliefs, e.g. "While it is true that evolution is a fact, there are issues that require an intelligent intervention to be explained". Participants answered on 5-point scale 
( 1 = totally disagree, 5 = totally agree). For the purposes of the present study, six items asking about the efficacy of specific CAM treatments were excluded from the questionnaire. Cronbach's alpha was .82.

\section{Cognitive predictors.}

Scientific reasoning was measured using items based on the Scientific reasoning scale (Drummond \& Fischhoff, 2017). For the present study, we used six items that were developed by Bašnáková et al. (2021). For example, the "causation vs correlation" item was about increasing birth rate: "A researcher wants to find out how to increase natality. He asks for statistical information and sees that there are more children born in cities that have more hospitals. This finding implies that building new hospitals will increase the birth rate of a population. Agree/Disagree". Each correct answer was assigned 1 point and we calculated the total score as the sum of all correct answers, thus a higher number indicates better scientific reasoning. Cronbach's alpha was .45 .

Cancer health literacy was measured by 11 items chosen from the CHLT-30 (Dumenci et al., 2014). The test contained multiple-choice questions, e.g.: "If a patient has stage 1 cancer, it means the cancer is ... (a) Localized, (b) In nearby organs, (c) In distant sites. For each correct answer, the participant received 1 point, so the higher score reflects higher health literacy. Cronbach's alpha was .44.

Health locus of control was measured by the Multidimensional Health Locus of Control (Wallston et al., 1978), which contained 18 questions in three subscales: Internal health locus of control (e.g. "If I get sick, it is my own behavior which determines how soon will I get well again.", Cronbach's alpha = .72), Powerful Others health locus of control (e.g. "Health professionals keep me healthy.", Cronbach's alpha = = .69), and Chance Health locus of control (e.g. "No matter what I do, if I am going to get sick, I will get sick.", Cronbach's alpha $=.69$ ).

Trust in doctors was measured by five items scale (Dugan et al., 2005), e.g., "Overall, I trust doctors completely." Participants answered on a 5-point scale ranging from 1 (total disagree) to 5 (totally agree). Cronbach's alpha was .76.

Composite variables. For simplicity and in order not to include multiple common predictors in the regression analyses predicting attitudes toward and use of CAM (see Table 2 below), we have created several composite variables for use in the regression analyses. First, composite magical and pseudoscientific health beliefs variable was created as a regression score extracted from the principal component analysis with three indicators - magical health beliefs, holistic health beliefs, and pseudoscientific beliefs (single component with eigenvalue $>1$ accounted for $59 \%$ of the variance). Secondly, the same approach was used to reduce the three loci of control dimensions into a single variable. A single external locus of control component with eigenvalue $>1$ was identified which accounted for $50 \%$ of the variance (internal locus of control variable loaded negatively onto the composite score). Finally, scientific reasoning and cancer health literacy scores were averaged into a single composite, both variables were standardized and their $z$-scores were averaged $(r=.36)$. These composite variables were used instead of individual scores in the regression analysis reported below. 


\section{Results}

\section{Prevalence of CAM use}

Only $4 \%$ of our sample used the CAM as the main method of treatment $(1.4 \%$ of women with and $2.9 \%$ women without cancer diagnosis); the majority used CAM only as complementary to the conventional medicine. However, $98.3 \%$ of participants had tried at least one CAM service, product or self-help during the last year. The average number of CAM services used in the last 12 months was $4.5(S D=2.3)$. The most often used CAM service in the last year was therapeutic massage (19.2\%), the most often used CAM products were vitamins/minerals ( $97.2 \%)$ followed by herbs/herbal medicine (71.2 \%), and the most often used CAM self-help was a prayer for health $(40.7 \%)$, followed by relaxation techniques $(39.6 \%)$ and aromatherapy (39.0\%).

\section{Correlations between variables and regression analysis}

To explore further relationships between variables, we performed correlation analysis (Table 1).

Table 1. Descriptive statistics and correlations between the main variables in the present study for the whole sample

\begin{tabular}{|c|c|c|c|c|c|c|c|c|c|c|c|c|c|c|c|c|}
\hline & $M$ & $S D$ & 1. & 2. & 3. & 4. & 5. & 6. & 7. & 8. & 9. & 10. & 11. & 12. & 13. & 14. \\
\hline 1. use of CAM services & 1.22 & 1.40 & 1 & & & & & & & & & & & & & \\
\hline 2. use of CAM products & 2.59 & 1.07 & .39 & 1 & & & & & & & & & & & & \\
\hline 3. use of CAM self-help & 2.80 & 1.79 & .33 & .32 & 1 & & & & & & & & & & & \\
\hline 4. use of CAM (total) & 6.62 & 3.22 & $(.75)$ & (.68) & (.81) & 1 & & & & & & & & & & \\
\hline 5. preference for CAM & 4.37 & 0.99 & -.26 & -.18 & -.31 & -.34 & 1 & & & & & & & & & \\
\hline 6. attitudes toward CAM & 14.9 & 4.88 & .28 & .32 & .28 & .39 & -.58 & 1 & & & & & & & & \\
\hline 7. magical health beliefs & 26.3 & 8.35 & .24 & .28 & .20 & .31 & -.39 & .50 & 1 & & & & & & & \\
\hline 8. holistic health beliefs & 22.1 & 2.89 & .16 & .23 & .35 & .34 & -.06 & .10 & .26 & 1 & & & & & & \\
\hline 9. pseudoscientific beliefs & 63.8 & 11.0 & .14 & .22 & .06 & .17 & -.21 & .39 & .63 & .22 & 1 & & & & & \\
\hline 10. scientific reasoning & 4.99 & 1.12 & -.07 & -.12 & .11 & -.01 & .06 & -.25 &.- .38 & -.09 & -.52 & 1 & & & & \\
\hline 11. cancer health literacy & 10.0 & 1.25 & .11 & .02 & .11 & .12 & .08 & -.10 & -.18 & .05 & -.29 & .36 & 1 & & & \\
\hline 12. internal locus of control & 19.1 & 3.84 & .11 & .14 & .16 & .19 & -.20 & .25 & .29 & .30 & .22 & -.15 & -.08 & 1 & & \\
\hline 13. others locus of control & 17.9 & 4.29 & -.11 & -.10 & -.11 & -.14 & .21 & -.27 & -.11 & -.02 & .02 & -.11 & -.08 & -.14 & 1 & \\
\hline 14. chance locus of control & 14.6 & 4.47 & -.08 & .10 & -.06 & -.03 & .11 & .04 & .13 & -.09 & .33 & -.30 & -.23 & -.30 & .31 & 1 \\
\hline 15. trust in doctors & 2.66 & 0.65 & .12 & .12 & .10 & .10 & -.21 & .30 & .09 & .13 & .19 & .00 & -.08 & -.02 & -.19 & .05 \\
\hline
\end{tabular}

Note. Correlations are based on 177 observations. Correlations in parentheses indicate part-whole relationships. Correlations of $r>.15$ are significant at $p<.05, r>.20$ are significant at $p<.01$, and $r>.25$ are significant at $p<.001$. Correlations that appear in bold are significant $(p<.05)$.

The results showed that the use of CAM correlated with all belief variables ( $r$-values ranging from .16 to .35), with the exception of pseudoscientific beliefs, which were related only to the use of CAM products ( $r$ $=.22$ ), but not CAM services or self-help practices. There was no correlation of CAM measures with scientific reasoning nor with cancer health literacy. A positive correlation was found between CAM use and internal locus of control $(r=.19)$. Scientific reasoning and cancer health literacy showed expected negative correlations with some of the belief measures (r-values ranging from -.18 to -.52).

Next, we proceeded to examine whether the use of CAM and attitudes toward CAM are best predicted by socio-demographic factors, beliefs, or cognitive factors, therefore we performed hierarchical regression analyses. Socio-demographic factors, such as age, education and cancer diagnosis were entered in the first step, factor score for magical beliefs, holistic health beliefs, pseudoscientific beliefs, locus of control, 
and trust in doctors was entered in the second step, and scientific reasoning and cancer health literacy composite score was entered in the third step. Results are shown in Table 2. 
Table 2. Summaries of linear regressions predicting CAM use and attitudes toward CAM CAM use total CAM preference CAM attitudes

$\begin{array}{llllll}\beta & p & \beta & p & \beta & p\end{array}$

Step 1

\begin{tabular}{lcccccc|} 
Age & .07 & .423 & -.02 & .794 & .13 & .123 \\
Education & .08 & .319 & .09 & .267 & .02 & .845 \\
Cancer diagnosis & -.14 & .094 & -.15 & .084 & .04 & .615 \\
\hline$F=0.827^{\text {n.s. }}$ & $R^{2}=.036, F=2.17^{\text {n.s. }}$ & $R^{2}=.023, F=1.39$ n.s. & $R^{2}=.014$ \\
\hline
\end{tabular}

Step 2

\begin{tabular}{|c|c|c|c|c|c|c|}
\hline Age & .02 & .855 & .04 & .614 & .05 & .552 \\
\hline Education & .08 & .273 & .08 & .273 & .03 & .636 \\
\hline Cancer diagnosis & -.18 & .046 & -.12 & .179 & .02 & .776 \\
\hline $\begin{array}{l}\text { Pseudoscientific and magical } \\
\text { health beliefs }\end{array}$ & .27 & $<.001$ & .30 & $<.001$ & .41 & $<.001$ \\
\hline Trust in doctors & .06 & .395 & .14 & .061 & .21 & .002 \\
\hline External locus of control & -.19 & .015 & .18 & .023 & -.16 & .027 \\
\hline 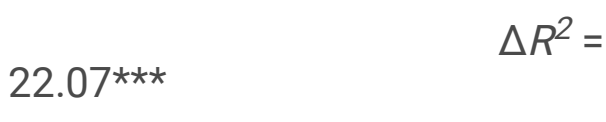 & $\Delta R^{2}=.128, F=8.67^{* *}$ & \multicolumn{3}{|c|}{$\Delta R^{2}=.161, F=11.15^{\star \star \star}$} & \multicolumn{2}{|c|}{$\Delta R^{2}=.276, F=$} \\
\hline \multicolumn{7}{|l|}{ Step 3} \\
\hline Age & .02 & .793 & .04 & .616 & .04 & .573 \\
\hline Education & .05 & .465 & .08 & .275 & .04 & .535 \\
\hline Cancer diagnosis & -.17 & .047 & -.12 & .180 & .02 & .790 \\
\hline $\begin{array}{l}\text { Pseudoscientific and magical } \\
\text { health beliefs }\end{array}$ & .36 & $<.001$ & -.30 & $<.001$ & .38 & $<.001$ \\
\hline Trust in doctors & .06 & .395 & -.14 & .062 & .21 & .002 \\
\hline External locus of control & -.16 & .044 & .18 & .026 & -.17 & .019 \\
\hline Reasoning \& literacy & .21 & .007 & -.01 & .949 & -.08 & .276 \\
\hline
\end{tabular}




$$
\begin{aligned}
& \Delta R^{2}=.035, F=7.34^{\star *} \\
& \Delta R^{2}=.000, F=0.00^{\text {n.s. }} \quad \Delta R^{2}=.005, F=1.19 \\
& \text { n.s. } \\
& F=7.52^{\text {** }} \\
& \Delta R^{2}=.034, \\
& \text { n.s. } \\
& \Delta R^{2}=.006, F=1.36
\end{aligned}
$$

Note. The table shows the results of three regressions predicting the use of CAM, preference for CAM over the classical medical treatment, and attitudes toward CAM. The results include standardized regression coefficients $(\beta)$ and their statistical significance, as well as explained variance in the outcome $\left(R^{2}\right)$ and its change $\left(\Delta R^{2}\right)$ at every step of the model. Significant predictors $(p<.05)$ are presented in bold. ** $p<.01, * \star \star p<.001$

Positive attitudes toward CAM were predicted mostly by pseudoscientific/magical beliefs, trust in doctors, and internal locus of control; reasoning and literacy did not seem to play a role in having more positive or negative attitudes toward CAM. Also, both use of CAM and the preference for CAM were predicted most strongly by pseudoscientific/magical beliefs and internal/external locus of control. Trust in doctors did not predict the use of CAM nor preference for CAM. However, the use of CAM was predicted also by having a cancer diagnosis and - unexpectedly - higher reasoning and literacy.

\section{Comparing women with diagnosis and without a diagnosis}

Lastly, we examined the differences between women with and without cancer diagnosis after controlling for differences in age and education. The statistical control for demographic factors was necessary as women without a cancer diagnosis were about 10 years younger on average $(M=34.16, S D=10.22)$ in comparison with women that have been diagnosed with cancer $(M=45.31, S D=9.79)(t=7.29, p<.001$, $d=1.11)$. Also, there was a marginally significant difference in education level, women diagnosed with cancer reported lower education $(M r a n k=80.84)$ than women without the diagnosis $(M r a n k=94.86), U=$ $3207, p=.050, r=.16$. Therefore, in further analyses, we controlled for the differences in age and education (Table 3). 
Table 3. The comparisons of all main variables between women with and without cancer diagnosis

\begin{tabular}{|c|c|c|c|c|c|c|c|}
\hline & \multicolumn{2}{|c|}{$\begin{array}{l}\text { with cancer } \\
\text { diagnosis }(n=74)\end{array}$} & \multicolumn{2}{|c|}{$\begin{array}{l}\text { without cancer } \\
\text { diagnosis }(n=103)\end{array}$} & \multicolumn{3}{|c|}{ pairwise comparison } \\
\hline & & $S E$ & $M$ & $S E$ & $t$ & $p$ & $d$ \\
\hline & $M$ & & & & & & \\
\hline use of CAM services & 1.39 & 0.170 & 1.10 & 0.141 & 1.25 & .212 & 0.22 \\
\hline $\begin{array}{l}\text { use of CAM } \\
\text { products }\end{array}$ & 2.70 & 0.134 & 2.52 & 0.111 & 1.01 & .315 & 0.18 \\
\hline $\begin{array}{l}\text { use of CAM self- } \\
\text { help practices }\end{array}$ & 3.07 & 0.226 & 2.61 & 0.187 & 1.47 & .144 & 0.26 \\
\hline total use of CAM & 7.16 & 0.403 & 6.22 & 0.334 & 1.68 & .094 & 0.30 \\
\hline preference for CAM & 4.54 & 0.124 & 4.24 & 0.103 & 1.74 & .084 & 0.31 \\
\hline $\begin{array}{l}\text { positive attitudes } \\
\text { toward CAM }\end{array}$ & 14.7 & 0.619 & 15.1 & 0.513 & $\overline{0} .504$ & .615 & 0.09 \\
\hline $\begin{array}{l}\text { magical health } \\
\text { beliefs }\end{array}$ & 27.1 & 1.030 & 25.8 & 0.853 & 0.947 & .345 & 0.17 \\
\hline $\begin{array}{l}\text { holistic health } \\
\text { beliefs scale }\end{array}$ & 22.4 & 0.366 & 21.8 & 0.303 & 1.11 & .268 & 0.19 \\
\hline $\begin{array}{l}\text { pseudoscientific } \\
\text { beliefs }\end{array}$ & 66.2 & 1.30 & 62.2 & 1.08 & 2.24 & .027 & 0.39 \\
\hline scientific reasoning & 4.75 & 0.135 & 5.16 & 0.112 & $\overline{2} .19$ & .030 & 0.38 \\
\hline $\begin{array}{l}\text { cancer health } \\
\text { literacy }\end{array}$ & 10.03 & 0.157 & 9.99 & 0.130 & 0.179 & .858 & 0.03 \\
\hline $\begin{array}{l}\text { internal locus of } \\
\text { control }\end{array}$ & 18.0 & 0.478 & 19.9 & 0.396 & $\overline{2.80}$ & .006 & 0.49 \\
\hline $\begin{array}{l}\text { powerful others } \\
\text { locus of control }\end{array}$ & 19.3 & 0.525 & 16.8 & 0.435 & 3.45 & $<.001$ & 0.61 \\
\hline $\begin{array}{l}\text { chance locus of } \\
\text { control }\end{array}$ & 15.7 & 0.532 & 13.8 & 0.440 & 2.51 & .013 & 0.44 \\
\hline trust in doctors & 2.54 & 0.082 & 2.74 & 0.068 & $\overline{1.71}$ & .090 & 0.30 \\
\hline
\end{tabular}

Note. The table presents the results of analyses of covariance with cancer diagnosis (with diagnosis / without diagnosis) as a fixed factor and age and education as covariates. The descriptives for the two groups are estimated marginal means (after controlling for age and education). The pairwise comparisons show the results of the $t$-tests based on the estimated marginal means, along with their statistical significance $(p)$ and effect size (Cohen's $d$ ) for the difference. 
After controlling for age and education, we found that women with cancer diagnosis had significantly more pseudoscientific beliefs than women without the diagnosis. Another significant difference was that women without cancer diagnosis have a higher internal locus of control over their health while women diagnosed with cancer felt that their health is more in the hands of their doctors or chance/destiny. There was no difference in cancer health literacy, but rather surprisingly, women without cancer diagnosis had higher scientific reasoning compared to women with cancer diagnosis.

\section{Discussion}

The main aim of this paper was to examine the predictive role of cognitive versus belief factors in CAM use and potential differences in cognitive and belief variables between women diagnosed and not diagnosed with cancer. The most important finding is that pseudoscientific/magical beliefs are the strongest predictor of positive attitudes toward CAM and its higher use, as well as using CAM instead of conventional treatment. Another factor that was the significant predictor of all three dependent variables was the external locus of control. On the other hand, cancer diagnosis predicted only higher CAM use (in line with findings of Buckner et al., 2018; DiGianni et al., 2002; Fox et al., 2013; Matsuno et al., 2012), but not more positive attitudes to CAM, nor using CAM instead of conventional medicine.

Before discussing our results in more detail we have to note that the prevalence of CAM use was not very high and there were marked differences dependent on the individual types of CAM. Although women with cancer used overall more CAM practices, there were only a few significant differences on the level of individual CAM practices (exceptions were: acupuncture, herbalist, and flour-free and chlorine-free water). Use of individual CAM practices ranged from as low as $1 \%$ (master mineral solution, naturopath) to $88 \%$ (herbs), with vitamins used by practically the whole sample (100\% women with a cancer diagnosis, $99 \%$ women without a cancer diagnosis). These results are generally in line with reports from other studies (Berretta et al., 2016; Harris et al., 2012; Keene et al., 2019). It seems that CAM services, such as visiting spiritual healer, chiropractic, homeopath, acupuncturist, and herbalist, are used by $14 \%$ to $34 \%$ of women with cancer, on the other hand, using self-help practices that are free or CAM products that are relatively cheap, is more prevalent and ranges from $36 \%$ to $88 \%$. The CAM methods that could be considered most useless or even dangerous, such as wearing magnetic bracelets, hypnotherapy, or MMS, are used by less than $12 \%$ women with cancer diagnosis in our sample.

Our results generally suggest that magical and pseudoscientific beliefs play the most important role in adopting positive attitudes toward CAM and the use of CAM, irrespective of a cancer diagnosis. Even though having cancer did predict higher use of CAM, pseudoscientific and magical beliefs remained the strongest predictor of CAM use. Thus, it seems that women who have an inclination toward holistic and magical beliefs about health tend to favor CAM treatments independently of the cancer diagnosis, although diagnosis of cancer also contributes to their higher use of CAM. In other words, it seems improbable that women would turn toward CAM treatment only after being diagnosed with cancer. 
Not at all surprising was also the finding that women with more internal locus of control use CAM more often than women with more external locus of control, who rely on the advice from their physicians. Women with more internal locus of control also tended to prefer CAM treatment over traditional treatment. The effect of internal locus of control was similarly strong as the effect of a cancer diagnosis.

Trust in doctors seems to play a role only in increasing the positive attitudes toward CAM. This was an unexpected result because we assumed that trust in doctors would play a role in decreasing attitudes toward CAM. But one possible explanation is that participants misinterpreted the word "doctor" and might not differentiate between holistic practitioners (who are not licensed to practice medicine) and medical doctors. Their answers could therefore indicate trust in both groups of specialists. It would be necessary for future research to clarify our focus only on medical doctors.

Another surprising finding was that literacy and reasoning was a significant predictor of higher CAM use. Upon further examination, we concluded that it is probably some statistical artifact, as there were no correlations between the measures of cancer health literacy and scientific reasoning on one hand and measures of CAM use on the other. Moreover, scientific reasoning and to a lesser extent also cancer health literacy correlated negatively with magical beliefs and pseudoscientific beliefs, and scientific reasoning correlated moderately negatively also with positive attitudes toward CAM - all results in the expected direction and in line with previous research (Čavojová et al., n.d.; Čavojová, Šrol, \& Jurkovič, 2020b; Čavojová \& Ersoy, 2020).

\section{Comparing women with diagnosis and without a diagnosis}

There was no difference between women with and without cancer diagnosis in using CAM after we controlled for age and education. Both groups of women seem to use a similar number of CAM treatments and both groups use it mostly to complement, not replace conventional medicine. Similarly, women in our sample had the similar level of magical beliefs, holistic health beliefs, and attitudes toward CAM regardless of their cancer diagnosis. However, women with cancer had significantly more pseudoscientific beliefs than women without cancer.

Women without cancer diagnosis showed a higher internal locus of control over their health, while women with cancer felt that their health is more in the hands of their doctors or chance/destiny (i.e. had a more external locus of control). This finding is in line with previous studies (Gibek \& Sacha, 2019; Ranchor et al., 2010) suggesting that people with cancer are more likely to be reliant on external sources of control, such as health workers or their family members than on internal sources. One possible explanation for this finding can relate to the perceived nature of cancer and also the extensive treatment with uncertain outcomes may reduce patients' beliefs in personal control over their illness.

Even after controlling for age and education, the women without cancer diagnosis in our sample had significantly higher scientific reasoning than women with cancer. This was probably due to the nature of our data collection - we used social networks for addressing women with cancer and we also advertised the survey on our institutional webpage. Although we can only speculate in this regard, it is possible that 
followers of the institutional webpage are more interested in our research than the general public and thus we succeeded only in addressing women with higher scientific reasoning who shared it with their contacts, but we were successful only in reaching rather limited and self-selected sample, while women with cancer that accessed our survey via cancer patients supporting groups were from more diverse background and possibly differed also in other variables besides scientific reasoning that we did not measure. We are well aware of the importance of collecting the data from the representative samples in future studies but collecting the data from cancer patients remains to be problematic.

\section{Limitations of the present research}

The main limitation of our research was a self-selected sample that did not allow to match women with and without cancer diagnosis on all relevant characteristics. Despite this limitation, we believe that our results contribute to our understanding of the factors that lead women to the use of CAM and that cancer diagnosis is not the crucial factor that makes women turn to CAM. We saw that even though women without a diagnosis in our sample were higher in scientific reasoning (possibly due to self-selection), still the main driving force to CAM was their magical and pseudoscientific beliefs. However, these results are tentative and need to be supported by further research on the larger and more representative sample. It would be also important to verify these results also on the general population including men.

Another limitation of the current research is the CAM questionnaire we used. Although it showed good psychometric properties, it focused our attention on possible cultural differences. Moreover, the subscale CAM services may be more dependent on the financial situation of a participant, and in the current research, it was also probably affected by ongoing COVID-19 pandemic, as due to the lockdown measures, many of services (not only CAM) were closed and unavailable. Similarly, the use of vitamins in this questionnaire is underspecified and could be also over-reported due to the pandemic (e.g., higher intake vitamin D was often recommended as prevention against COVID-19). Also, in the next research, we would like to focus more on CAM practices that are possibly more harmful.

\section{Conclusion}

In this paper, we focused on predictors of CAM use and attitudes in women with and without cancer diagnosis and whether these two groups differ in these predictor variables, as most research focus usually either on the general population or cancer patients. The main contribution of our study was that even though women in our sample differed in some predictor variables, such as locus of control, pseudoscientific beliefs, and science reasoning, the strongest predictor of CAM use and attitudes were pseudoscientific and magical beliefs about health. Positive attitudes toward CAM were further predicted by an internal locus of control and trust in doctors, while CAM use was further predicted by a cancer diagnosis and internal locus of control. The positive aspect of our results was also finding that only a few women prefer CAM treatment over conventional treatment and that most reported used CAM treatments were relatively harmless. The study also highlighted the need for more precise CAM measurement, as there are many conceptualizations of what actually comprises CAM and that we need to understand 
better the motivations of people turning to CAM treatments. Moreover, there are many grey areas, because some complementary treatments are prescribed even by physicians and others CAM treatments proved to be effective for some diagnoses (e.g. massages, yoga, or body manipulations techniques for alleviating spinal pain), but sometimes are used for completely different purposes (e.g. some of the pseudoscientific beliefs and conspiracy theories against CAM were shared by esoteric groups and yoga instructors). Also, there is a difference if people wear crystals for aesthetic purposes mainly (while harboring irrational beliefs that it will also help them to open the chakras and/or get rid of some mild symptoms) or if they truly believe that wearing such crystals will protect them against COVID-19 or will cure their cancer. Maybe there is no harm if a cancer patient believes that her breast cancer was caused by blocked emotions arising from maternal conflict and let some life coach "unblock" it by magnets when she still follows recommended regimen of treatments; however, such esoteric beliefs tend to cluster together (Lobato et al., 2014) to provide the nutritional ground for more dangerous conspiracy theories (Brotherton, 2015) and subsequent refusal of the more effective interventions and should not be taken lightly (van Mulukom et al., n.d.).

\section{Declarations}

\section{Ethics approval and consent to participate}

All methods were carried out in accordance with APA standards and ethical requirements of Slovak Academy of Sciences. The study was approved by the Ethical Committee of the Center for Social and Psychological Sciences, SAS. Informed consent was obtained from all subjects.

\section{Consent for publication}

The authors agree with the publication of the manuscript.

\section{Availability of data and materials}

All data and materials used in this study will be available upon publication at: https://osf.io/ghycv/. Data and materials avaliable for the blind review are at: https://osf.io/ghycv/? view_only=d42e21ccf0624479a811d56c2d6c4ef5.

\section{Competing interests}

The Authors declare that there is no conflict of interest.

\section{Funding}

This research is part of project "Integrative strategy in development of personalized medicine of selected malign oncological diseases and its effect on the quality of life" (313011V446) and it was also funded by Slovak Research Development Agency under grant number APVV-20-0335. 
V.Č. and Z.K. wrote the main manuscript text. V.Č. and J.Š. analyzed the data. J.Š. prepared tables 1 - 3. All authors contributed to the design of the study, prepared the materials, collected the data and revised the manuscript.

\section{Acknowledgements}

We thank Michal Kohút with designing the survey in Qualtrics.

\section{References}

1. Abheiden, H., Teut, M., \& Berghöfer, A. (2020). Predictors of the use and approval of CAM: results from the German General Social Survey (ALLBUS). BMC Complementary Medicine and Therapies 2020 20:1, 20(1), 1-11. https://doi.org/10.1186/S12906-020-02966-9

2. Ajzen, I. (2002). Perceived Behavioral Control, Self-Efficacy, Locus of Control, and the Theory of Planned Behavior ${ }^{1}$. Journal of Applied Social Psychology, 32(4), 665-683. https://doi.org/10.1111/j.1559-1816.2002.tb00236.x

3. Astin, J. A. (1998). Why patients use alternative medicine. JAMA, 279(19), 1548-1553. https://doi.org/10.1001/jama.279.19.1548

4. Bašnáková, J., Čavojová, V., \& Šrol, J. (2021). Does concrete content help people to reason scientifically? Adaptation of Scientific reasoning scale. Science \& Education. https://doi.org/https://doi.org/10.1007/s11191-021-00207-0

5. Berretta, M., Pepa, C. Della, Tralongo, P., Fulvi, A., Martellotta, F., Lleshi, A., Nasti, G., Fisichella, R., Romano, C., Divitiis, C. De, Taibi, R., Fiorica, F., Francia, R. Di, Mari, A. Di, Pup, L. Del, Crispo, A., Paoli, P. De, Santorelli, A., Quagliariello, V., ... Facchini, G. (2016). Use of Complementary and Alternative Medicine (CAM) in cancer patients: An Italian multicenter survey. Oncotarget, 8(15), 24401-24414. https://doi.org/10.18632/ONCOTARGET.14224

6. Bishop, F. L., \& Lewith, G. T. (2010). Who uses CAM? A narrative review of demographic characteristics and health factors associated with CAM use. Evidence-Based Complementary and Alternative Medicine: ECAM, 7(1), 11-28. https://doi.org/10.1093/ecam/nen023

7. Boutin, P. D., Buchwald, D., Robinson, L., \& Collier, A. C. (2000). Use of and attitudes about alternative and complementary therapies among outpatients and physicians at a municipal hospital. The Journal of Alternative and Complementary Medicine, 6(4), 335-343. https://doi.org/10.1089/10755530050120709

8. Brotherton, R. (2015). Suspicious Minds: Why We Believe Conspiracy Theories. Bloomsbury.

9. Bryden, G. M., Browne, M., Rockloff, M., \& Unsworth, C. (2018). Anti-vaccination and pro-CAM attitudes both reflect magical beliefs about health. Vaccine, 36(9), 1227-1234. https://doi.org/10.1016/j.vaccine.2017.12.068

10. Buckner, C. A., Lafrenie, R. M., Dénommée, J. A., Caswell, J. M., \& Want, D. A. (2018). Complementary and Alternative Medicine Use in Patients Before and After a Cancer Diagnosis. Current Oncology 
2018, Vol. 25, Pages 275-281, 25(4), 275-281. https://doi.org/10.3747/C0.25.3884

11. Catt, S., Fallowfield, L., \& Langridge, C. (2006). What non-prescription treatments do UK women with breast cancer use? European Journal of Cancer Care, 15(3), 279-285.

https://doi.org/10.1111/J.1365-2354.2006.00652.X

12. Čavojová, V., \& Ersoy, S. (2020). The role of scientific reasoning and religious beliefs in use of complementary and alternative medicine. Journal of Public Health.

https://doi.org/10.1093/pubmed/fdz120

13. Čavojová, V., Mikušková, E. B., \& Šrol, J. (2022). Being nice or being scared? Personality traits, beliefs and threat of COVID-19 as predictors of non-normative health behaviors during second wave of pandemic. Studia Psychologica, 64(2).

14. Čavojová, V., Šrol, J., \& Ballová Mikušková, E. (2020). How scientific reasoning correlates with healthrelated beliefs and behaviors during the COVID-19 pandemic? Journal of Health Psychology. https://doi.org/10.1177/1359105320962266

15. Čavojová, V., Šrol, J., \& Jurkovič, M. (2020a). Why should we try to think like scientists? Scientific reasoning and susceptibility to epistemically suspect beliefs and cognitive biases. Applied Cognitive Psychology, 34(1). https://doi.org/10.1002/acp.3595

16. Čavojová, V., Šrol, J., \& Jurkovič, M. (2020b). Why should we try to think like scientists? The role of scientific reasoning in susceptibility to epistemically suspect beliefs and cognitive biases. Journal of Applied Cognitive Psychology, 34(1), 85-95. https://doi.org/https://doi.org/10.1002/acp.3595

17. Čavojová, V., Šrol, J., \& Mikušková, E. B. (n.d.). With the little help of science understanding: Examining the direct and indirect role of scientific reasoning and trust in science in normative health behaviour during pandemic. Preprint. https://doi.org/10.31234/OSF.IO/XAHDJ

18. Conrady, D. von, \& Bonney, A. D. (2017). Patterns of complementary and alternative medicine use and health literacy in general practice patients in urban and regional Australia. Australian Family Physician, 46(5), 316-320.

19. Dieckmann, N. F., \& Johnson, B. B. (2019). Why do scientists disagree? Explaining and improving measures of the perceived causes of scientific disputes. Plos One, 14(2), e0211269. https://doi.org/10.1371/journal.pone.0211269

20. DiGianni, L. M., Garber, J. E., \& Winer, E. P. (2002). Complementary and alternative medicine use among women with breast cancer. Journal of Clinical Oncology: Official Journal of the American Society of Clinical Oncology, 20(18 Supp, 34S-38S.

21. Dişsiz, G., \& Yilmaz, M. (2016). Complementary and alternative therapies and health literacy in cancer patients. Complementary Therapies in Clinical Practice, 23, 34-39.

https://doi.org/10.1016/J.CTCP.2016.02.004

22. Downs, J. S., de Bruin, W. B., \& Fischhoff, B. (2008). Parents' vaccination comprehension and decisions. Vaccine, 26(12), 1595-1607. https://doi.org/10.1016/j.vaccine.2008.01.011

23. Drummond, C., \& Fischhoff, B. (2017). Development and validation of the Scientific Reasoning Scale. Journal of Behavioral Decision Making, 30(1), 26-38. https://doi.org/10.1002/bdm.1906 
24. Dubois, C., Eisfeld, H., Bauer, F., Schmidt, T., Kastrati, K., Hochhaus, A., \& Hübner, J. (2019). Not all cancer patients with an interest in CAM are the same. Differences between patients with a CAM interest prior to the cancer diagnosis and those with first-time interest since diagnosis. Complementary Therapies in Medicine, 45(May), 167-171.

https://doi.org/10.1016/j.ctim.2019.06.009

25. Dugan, E., Trachtenberg, F., \& Hall, M. A. (2005). Development of abbreviated measures to assess patient trust in a physician, a health insurer, and the medical profession. BMC Health Services Research 2005 5:1, 5(1), 1-7. https://doi.org/10.1186/1472-6963-5-64

26. Dumenci, L., Matsuyama, R., Riddle, D. L., Cartwright, L. A., Perera, R. A., Chung, H., \& Siminoff, L. A. (2014). Measurement of Cancer Health Literacy and Identification of Patients with Limited Cancer Health Literacy. Journal of Health Communication, 19(0 2), 205. https://doi.org/10.1080/10810730.2014.943377

27. Ernst, E. (2007). 'First, do no harm' with complementary and alternative medicine. Trends in Pharmacological Sciences, 28(2), 48-50. https://doi.org/10.1016/J.TIPS.2006.12.008

28. Fasce, A., \& Picó, A. (2019). Conceptual foundations and validation of the Pseudoscientific Belief Scale. Applied Cognitive Psychology, 1-12. https://doi.org/10.1002/acp.3501

29. Fouladbakhsh, J. M., \& Stommel, M. (2008). Comparative Analysis of CAM Use in the U.S. Cancer and Noncancer Populations. Journal of Complementary and Integrative Medicine, 5(1). https://doi.org/10.2202/1553-3840.1140

30. Fouladbakhsh, J. M., \& Stommel, M. (2009). Gender, Symptom Experience, and Use of Complementary and Alternative Medicine Practices Among Cancer Survivors in the U.S. Cancer Population. Oncology Nursing Forum, 37(1), E7-E15. https://doi.org/10.1188/10.0NF.E7-E15

31. Fox, P., Butler, M., Coughlan, B., Murray, M., Boland, N., Hanan, T., Murphy, H., Forrester, P., Brien, M. O., \& Sullivan, N. O. (2013). Using a mixed methods research design to investigate complementary alternative medicine (CAM) use among women with breast cancer in Ireland. European Journal of Oncology Nursing, 17(4), 490-497. https://doi.org/10.1016/J.EJON.2012.10.008

32. Gibek, K., \& Sacha, T. (2019). Comparison of health locus of control in oncological and nononcological patients. Contemporary Oncology/Wspótczesna Onkologia, 23(2), 115-120. https://doi.org/10.5114/W0.2019.85638

33. Greenberg, J., Solomon, S., \& Pyszczynski, T. (1997). Terror Management Theory of Self-Esteem and Cultural Worldviews: Empirical Assessments and Conceptual Refinements. Advances in Experimental Social Psychology, 29(C), 61-139. https://doi.org/10.1016/S0065-2601(08)60016-7

34. Harris, P. E., Cooper, K. L., Relton, C., \& Thomas, K. J. (2012). Prevalence of complementary and alternative medicine (CAM) use by the general population: a systematic review and update. International Journal of Clinical Practice, 66(10), 924-939. https://doi.org/10.1111/J.17421241.2012.02945.X

35. Henderson, J. W., \& Donatelle, R. J. (2003). The relationship between cancer locus of control and complementary and alternative medicine use by women diagnosed with breast cancer. Psycho- 
Oncology, 12(1), 59-67. https://doi.org/10.1002/PON.636

36. Hyland, M. E., Lewith, G. T., \& Westoby, C. (2003). Developing a measure of attitudes: The holistic complementary and alternative medicine questionnaire. Complementary Therapies in Medicine, 11(1), 33-38. https://doi.org/10.1016/S0965-2299(02)00113-9

37. Jablotschkin, M., Bartsch, H. H., Gschwendtner, K., Hauer, J., Horneber, M., \& Weis, J. (2020). Educational Program in Complementary and Alternative Medicine for Cancer Self-Help Groups. Complementary Medicine Research, 27(4), 222-229. https://doi.org/10.1159/000504315

38. Johnson, S. B., Park, H. S., Gross, C. P., \& Yu, J. B. (2018). Use of alternative medicine for cancer and its impact on survival. JNCl: Journal of the National Cancer Institute, 110(1), 121-124. https://doi.org/10.1093/jnci/djx145

39. Kaygısız, G. M., \& Gürkan, B. (2018). Adaptation of Scientific Reasoning Scale into Turkish and Examination of its Psychometric Properties. Educational Sciences: Theory \& Practice, 18(3), 737757. https://doi.org/10.12738/estp.2018.3.0175

40. Keene, M. R., Heslop, I. M., Sabesan, S. S., \& Glass, B. D. (2019). Complementary and alternative medicine use in cancer: A systematic review. Complementary Therapies in Clinical Practice, 35, 3347. https://doi.org/10.1016/j.ctcp.2019.01.004

41. Kristoffersen, A. E., Stub, T., Salamonsen, A., Musial, F., \& Hamberg, K. (2014). Gender differences in prevalence and associations for use of CAM in a large population study. BMC Complementary and Alternative Medicine 2014 14:1, 14(1), 1-9. https://doi.org/10.1186/1472-6882-14-463

42. Latte-Naor, S., Sidlow, R., Sun, L., Li, Q. S., \& Mao, J. J. (2018). Influence of family on expected benefits of complementary and alternative medicine (CAM) in cancer patients. Supportive Care in Cancer 2018 26:6, 26(6), 2063-2069. https:// doi.org/10.1007/S00520-018-4053-0

43. Lindeman, M. (2011). Biases in intuitive reasoning and belief in complementary and alternative medicine. Psychology \& Health, 26(3), 371-382. https://doi.org/10.1080/08870440903440707

44. Lindeman, M., Keskivaara, P., \& Roschier, M. (2000). Assessment of Magical Beliefs about Food and Health. Journal of Health Psychology, 5(2), 195-209.

https://doi.org/10.1177/135910530000500210

45. Lobato, E. J. C., Mendoza, J., Sims, V., \& Chin, M. (2014). Examining the relationship between conspiracy theories, paranormal beliefs, and pseudoscience acceptance among a university population. Applied Cognitive Psychology, 28(5), 617-625. https://doi.org/10.1002/acp.3042

46. MacLennan, A. H., Myers, S. P., \& Taylor, A. W. (2006). The continuing use of complementary and alternative medicine in South Australia: costs and beliefs in 2004. The Medical Journal of Australia, 184(1), 27-31. http://www.ncbi.nlm.nih.gov/pubmed/16398628

47. MacLennan, A. H., Wilson, D. H., \& Taylor, A. W. (2002). The escalating cost and prevalence of alternative medicine. Preventive Medicine, 35(2), 166-173.

http://www.ncbi.nlm.nih.gov/pubmed/12200102

48. Matsuno, R. K., Pagano, I. S., Maskarinec, G., Issell, B. F., \& Gotay, C. C. (2012). Complementary and Alternative Medicine Use and Breast Cancer Prognosis: A Pooled Analysis of Four Population-Based 
Studies of Breast Cancer Survivors. Https://Home.Liebertpub.Com/Jwh, 21(12), 1252-1258. https://doi.org/10.1089/JWH.2012.3698

49. McFarland, B., Bigelow, D., Zani, B., Newsom, J., \& Kaplan, M. (2002). Complementary and Alternative Medicine Use in Canada and the United States. American Journal of Public Health, 92(10), 16161618. https://doi.org/10.2105/AJPH.92.10.1616

50. Meijerman, I., Beijnen, J. H., \& Schellens, J. H. M. (2006). Clinical Pharmacology Herb-Drug Interactions in Oncology: Focus on Mechanisms of Induction. The Oncologist, 11, 742-752. https://doi.org/10.1634/theoncologist.11-7-742

51. Myers, S. P., \& Cheras, P. A. (2004). The other side of the coin: safety of complementary and alternative medicine. Medical Journal of Australia, 181(4), 222-225. https://doi.org/10.5694/J.13265377.2004.TB06244.X

52. Pedersen, C. G., Christensen, S., Jensen, A. B., \& Zachariae, R. (2009). Prevalence, socio-demographic and clinical predictors of post-diagnostic utilisation of different types of complementary and alternative medicine (CAM) in a nationwide cohort of Danish women treated for primary breast cancer. European Journal of Cancer, 45(18), 3172-3181.

https://doi.org/10.1016/J.EJCA.2009.09.005

53. Pitel, L., \& Ballová Mikušková, E. (2021). The Irrational Health Beliefs Scale and Health Behaviors in a Non-Clinical Population. European Journal of Health Psychology, 28(3), 111-119. https://doi.org/10.1027/2512-8442/a000075

54. Rakovitch, E., Pignol, J.-P., Chartier, C., Ezer, M., Verma, S., Dranitsaris, G., \& Clemons, M. (2005). Complementary and alternative medicine use is associated with an increased perception of breast cancer risk and death. Breast Cancer Research and Treatment 2005 90:2, 90(2), 139-148. https://doi.org/10.1007/S10549-004-3779-1

55. Ranchor, A. V., Wardle, J., Steptoe, A., Henselmans, I., Ormel, J., \& Sanderman, R. (2010). The adaptive role of perceived control before and after cancer diagnosis: A prospective study. Social Science \& Medicine, 70(11), 1825-1831. https://doi.org/10.1016/J.SOCSCIMED.2009.10.069

56. Saher, M., \& Lindeman, M. (2005). Alternative medicine: A psychological persepctive. Personality and Individual Differences, 39(6), 1169-1178. https://doi.org/10.1016/j.paid.2005.04.008

57. Smith, P. J., Clavarino, A. M., Long, J. E., \& Steadman, K. J. (2015). Evaluation of a patient CAM-withchemotherapy educational brochure. Evidence-Based Complementary and Alternative Medicine, 2015. https://doi.org/10.1155/2015/408430

58. Šrol, J. (2020). Individual differences in epistemically suspect beliefs: The role of susceptibility to cognitive biases. https://doi.org/10.31234/osf.io/4jcf7

59. Šrol, J., Mikušková, E. B., \& Čavojová, V. (2021). When we are worried, what are we thinking? Anxiety, lack of control, and conspiracy beliefs amidst the COVID-19 pandemic. Applied Cognitive Psychology, 35(3), 720-729. https://doi.org/10.1002/acp.3798

60. Sugavanam, S. C., Sugavanam, S. C., \& Natarajan, B. (2020). Pseudoscientific beliefs and practices in the COVID-19 pandemic: A narrative review of unwanted experiments attributed to social media- 
based misinformation afflicting the public health. Journal of Health \& Biological Sciences, 8(1), 1-9. https://doi.org/10.12662/2317-3076jhbs.v8i1.3394.p1-9.2020

61. Teovanović, P., Lukić, P., Zupan, Z., Lazić, A., Ninković, M., \& Žeželj, I. (2020). Irrational beliefs differentially predict adherence to guidelines and pseudoscientific practices during the COVID-19 pandemic. Applied Cognitive Psychology, May, 1-11. https://doi.org/10.1002/acp.3770

62. Thomas, K., \& Coleman, P. (2004). Use of complementary or alternative medicine in a general population in Great Britain. Results from the National Omnibus survey. Journal of Public Health, 26(2), 152-157. https://doi.org/10.1093/pubmed/fdh139

63. Travers, J. C., Ayers, K., Simpson, R. L., \& Crutchfield, S. (2016). Fad, Pseudoscientific, and Controversial Interventions. 257-293. https://doi.org/10.1007/978-3-319-30925-5_9

64. van den Brink-Muinen, A., \& Rijken, P. (2006). Does trust in health care influence the use of complementary and alternative medicine by chronically ill people? BMC Public Health 2006 6:1, 6(1), 1-9. https://doi.org/10.1186/1471-2458-6-188

65. van Mulukom, V., Pummerer, L. J., Alper, S., Bai, H. M., Čavojová, V., Banai, I. P., Šrol, J., \& Iris, Ž. (n.d.). Antecedents and consequences of COVID-19 conspiracy theories: a rapid review of the evidence. 138.

66. Verhoef, M. J., Balneaves, L. G., Boon, H. S., \& Vroegindewey, A. (2005). Reasons for and characteristics associated with complementary and alternative medicine use among adult cancer patients: A systematic review. In Integrative Cancer Therapies (Vol. 4, Issue 4, pp. 274-286). Sage PublicationsSage CA: Thousand Oaks, CA. https://doi.org/10.1177/1534735405282361

67. Wallston, K. a, Wallston, B. S., \& Devellis, R. (1978). Development of the Multidimensional Health Locus of Control (MHLC) Scales. Health Education Monographs, 6(2), 160-170.

68. Wilhelm, M., \& Euteneuer, F. (2021). Does Health Literacy Make a Difference? Comparing the Effect of Conventional Medicine Versus Homeopathic Prescribing on Treatment Credibility and Expectancy. Frontiers in Psychology, 0, 1859. https://doi.org/10.3389/FPSYG.2021.581255

69. Xue, C. C. L., Zhang, A. L., Lin, V., Da Costa, C., \& Story, D. F. (2007). Complementary and Alternative Medicine Use in Australia: A National Population-Based Survey. The Journal of Alternative and Complementary Medicine, 13(6), 643-650. https://doi.org/10.1089/acm.2006.6355 